\title{
Desarrollo de competencias emprendedoras: Un análisis explicativo con estudiantes universitarios
}

\author{
Roberto ESPÍRITU OLMOS \\ Universidad de Colima, México \\ olmos@ucol.mx \\ Renato Francisco GONZÁLEZ SÁNCHEZ \\ Universidad de Colima, México \\ Refragosa67@gmail.com \\ Esteban ALCARAZ VERA \\ Universidad de Colima, México \\ Esteban7@ucol.mx
}

Recibido: 26-04-2012

Aceptado: 17-11-2012

\begin{abstract}
RESUMEN
Los cambios que se presentan en la sociedad y en el mundo deben ser tomados en cuenta por las universidades y no quedarse pasivas si no participar de manera activa. En la presente investigación se trata de analizar el grado de competencias emprendedoras que tienen los estudiantes universitarios así como el rol que juegan los docentes con el fin de conocer si se está incentivando la actitud emprendedora entre sus estudiantes. Las hipótesis planteadas acerca de las competencias que desarrollan los estudiantes, son contrastadas utilizando una muestra de 315 estudiantes de una Universidad mexicana. De acuerdo a los resultados se observó que existe una mayor probabilidad de intención emprendedora en los estudiantes de la carrera Licenciado en Administración que los del área Contable, además, es mayor en los hombres que en las mujeres y los estudiantes de mayor edad son quienes más probabilidad tienen de ser empresarios.
\end{abstract}

Palabras clave: Competencias emprendedoras, Intención emprendedora rol docente, cultura emprendedora. 


\title{
Development of entrepreneurial competencies: An explanatory analysis with university students
}

\begin{abstract}
In this research we analyze the extent of entrepreneurial competencies of the college students, as well as the role that play the teachers, so we can know whether the entrepreneurial attitude is encouraged among their students. The hypotheses about the competencies that students develop are contrasted by a sample of 315 students from a Mexican university. According to the results, it's noticed that there is more probability of entrepreneurial intention in the students from the Faculty of Business Administration than there is in the students of Accounting. Also, the probability is higher in men than in women, and older students are more likely to become entrepreneurs.
\end{abstract}

Keywords: Entrepreneurial competencies, entrepreneurial intention, teacher's role, entrepreneurial culture.

Sumario: 1. Introducción. 2. Revisión de literatura. 3. Materiales y métodos. 4. Resultados. 5. Conclusiones. Bibliografía.

\section{INTRODUCCIÓN}

El emprendimiento es uno de los temas que merece una atención puntual dentro de las universidades públicas y en general en todos los niveles educativos del país. Cabellos (2006) menciona que es un tema que se apodera de las labores de personas involucradas en el entorno universitario y que éste, al igual que la creación de fuentes de empleo, se han vuelto en temas de mucho interés debido a la actual crisis laboral que se vive y que perjudica a varios países producto de los cambios y transformaciones políticas y tecnológicas, así como las crisis financieras que han forzado bancarrotas a nivel personal, empresarial y gubernamental, trayendo como secuela graves problemas en el campo de trabajo.

Y debido a ello, menciona que es necesario que surjan opciones innovadoras entre las cuales se encuentra el emprendimiento y como su actor principal, el emprendedor apto para producir nuevas fuentes de empleo. Toca (2010) lo define como aquel que "asume riesgos, persigue algún beneficio; innova, identifica y crea oportunidades; establece y coordina nuevas combinaciones de recursos; y concibe nuevas formas de hacer las cosas". Tomando en cuenta lo antes mencionado, el impulso económico de un país depende de personas emprendedoras con la capacidad para idear soluciones competitivas e innovadoras, que impulsen el desarrollo de nuevas formas de progreso e impacten en el desempeño económico local, regional y nacional.

El presente proyecto pretende identificar las causas que influyen en el desarrollo de competencias emprendedoras en estudiantes universitarios. 


\section{Justificación}

Ante los retos y procesos de cambio que ha ido teniendo la sociedad actual, la universidad no debe quedarse pasiva y por lo tanto, debe participar de manera activa en el estudio de las problemáticas que aquejan a la sociedad, debe proponer ideas y acciones, intercambiar información, movilizar a la sociedad y tener la responsabilidad de favorecer la puesta en marcha de esas acciones (Campos y Sánchez, 2005). Uno de los retos que tiene toda Universidad para dar respuesta a esta necesidad, es la formación integral de sus estudiantes capaces de enfrentarse a las adversidades que emanan del mundo social y laboral.

La aseveración de Martínez (2008), no es ajena al contexto local y nacional e internacional. Con esta situación se confirma la importancia de realizar un trabajo como porque a su culminación se podrán crear modelos o propuestas de mejora en los procesos de formación y difusión del espíritu empresarial en beneficio de los estudiantes, y contribuir en el desarrollo de una cultura emprendedora, formando universitarios emprendedores y con visión empresarial que estén al tanto y conozcan las necesidades de nuestra economía y sociedad.

Así, "combinar el potencial educativo y el científico con las cualificaciones empresariales mediante el desarrollo de competencias emprendedoras posibilitará el aprovechamiento de los resultados académicos y los logros de la investigación científica para alcanzar progresos en el avance, innovación y mejora de la sociedad actual" (Sobrado y Fernández, 2010).

Pregunta de investigación. De acuerdo a las consideraciones anteriores se plantea la siguiente pregunta de investigación:

¿Cuáles son las condiciones al interior de la Universidad pública que permiten al estudiante ser emprendedor?

Hipótesis. Como hipótesis de trabajo, se consideran que existen elementos generales que impulsan o limitan el espíritu emprendedor de los estudiantes. La hipótesis general es que el papel de los profesores, el currículo de materias, la percepción de un estudiante sobre sus capacidades empresariales, así como algunas características socioeconómicas (edad, género, tipo de carrera) influyen en la generación habilidades empresariales del estudiante. Por lo tanto se plantean las siguientes:

H1. Los programas educativos del área Contable y Licenciado en Administración a partir del contenido de las materias, propician positivamente el desarrollo de competencias emprendedoras en los estudiantes.

H2. El rol que asume el docente influye positivamente en el fortalecimiento del espíritu empresarial en los estudiantes universitarios.

H3. La percepción positiva del estudiante universitario sobre su perfil emprendedor $\mathrm{y}$ sus aspiraciones empresariales influye positivamente en el desarrollo y fortalecimiento de sus competencias emprendedoras. 


\section{REVISIÓN DE LITERATURA}

Para tener en cuenta la intención del presente trabajo, es necesario conocer los conceptos y enfoques que diversos autores tienen acerca del emprendimiento y emprendedor, la enseñanza en emprendimiento y el rol del docente, competencias emprendedoras, y cultura emprendedora, lo cual nos dará una visión más amplia del tema.

\section{Emprendimiento y emprendedor}

Gutiérrez (2006), describe el emprendimiento como una capacidad para realizar proyectos de acción en un entorno de oportunidades identificadas, con la suficiente determinación para organizar los medios y recursos para aplicarlo. Es además, "un comportamiento individual y colectivo que implica atributos y competencias básicas y algunas extraordinarias que viabilizan la posibilidad de la acción por emprender". Amorós (2011), menciona que otras de las actitudes importantes que se incluyen dentro del emprendimiento son: el nivel de riesgo que el individuo está dispuesto a soportar y la visión que tiene de sus propias habilidades, conocimientos y experiencia en la creación de un negocio.

Dentro del documento, El Libro Verde de la Comisión de las Comunidades Europeas (2003), se define el emprendimiento como un "modelo mental y el proceso de crear y desarrollar una actividad económica combinando con cierto talante gerencial, riesgo con creatividad y/o innovación, bien sea, en una organización nueva o en una existente". Este ha sido "vinculado con riqueza, empresa, cambio, empleo, valor, crecimiento, pero posiblemente, la perspectiva más asociada ha sido la de innovación" (Toca, 2010).

Asimismo, el emprendimiento establece los objetivos que se pretenden alcanzar después de haber identificado los recursos para su realización, y se centra en la imaginación y en la creatividad. Éste debe verse como el impulsor de iniciativas, especialmente en aquellas, que poseen un objetivo social, toda vez que en las organizaciones se entrelazan relaciones y redes de colaboración, que hacen posibles la ejecución de proyectos. "El emprendimiento es, actualmente, el más llamado a presentar soluciones concretas, frente a los desafíos económicos y sociales con los que se enfrenta la sociedad" (Orrego, 2008).

Por lo tanto, con lo anteriormente escrito, se puede asentar que el emprendimiento en un acto que conlleva hacer realidad las ideas y oportunidades que han sido identificadas por individuos o colectivos en un contexto determinado. $\mathrm{Y}$ dentro de este acto podemos identificar la figura del emprendedor como el actor principal del emprendimiento y el desarrollo económico. Krauss (2008), menciona que diversos organismos internacionales y autores han reconocido la importancia de los emprendedores a la hora de considerar el desarrollo económico de los distintos países. Debido a que ellos "crean trabajo a partir de la innovación, la 
competitividad, la productividad, el capital de riesgo, transformando la economía y el mundo".

Existen diversos conceptos de emprendedor, según Orrego (2008), la palabra emprendedor deriva del vocablo latino prenderé que significa "acometer" e "intentar" y que se utilizó para referirse a los pioneros que decidían correr riesgos o lanzarse a una aventura; a la postre, los economistas enriquecieron el término hasta llegar a identificarlo con la innovación constante; actualmente en el campo administrativo, el emprendedor es el que evalúa los beneficios, riesgos y responde de manera positiva a los cambios con nuevas ideas y formas de hacer las cosas. Morales (2010), menciona que "la literatura del área del entrepreneurship ha mostrado que los emprendedores suelen presentar ciertas características comunes, como por ejemplo, la existencia de modelos de roles empresariales en su contexto familiar y laboral, predisposición a tomar riesgos calculados y experiencia en creación de empresas, entre otras".

En este sentido, también el contexto familiar y laboral que se constituyen como rasgos no psicológicos, ejerce una influencia en el perfil emprendedor. López, Montilla y Briceño (2007), argumentan que existen evidencias empíricas que demuestran que grandes empresarios descienden de familiares que fueron empresarios, lo que demuestra que de ser así, aumenta la posibilidad que los descendientes repitan patrones de un comportamiento emprendedor. Asimismo, también se suman la experiencia y educación del emprendedor, lo que permite que se conviertan en "habilidades adquiridas", las cuales se suman a los atributos personales. En su conjunto, las habilidades, la experiencia y la educación, generan la motivación del emprendedor y esta motivación, junto con los factores ambientales, llevan al emprendedor a manifestar conductas. Con esta representación se entiende "el proceso de emprendimiento como un proceso dinámico" (Baron y Shane, 2008).

\section{La enseñanza emprendedora y el rol docente}

Si la educación es un pilar en ese proceso al que se refieren Baron y Shane (2008), entonces, la escuela debe contribuir a la formación de una educación empresarial o en emprendimiento ya que en la Universidad actual, según Vigorena (2006), se deben generar las nuevas ideas que logren transformar a la sociedad. La educación emprendedora es una opción, ya que ésta se encamina a ofrecer a los estudiantes de cualquier nivel, el desarrollo de competencias, capacidades e instrumentos para que se forme como un actor de desarrollo económico y social, genera jóvenes independientes, innovadores, creativos, emprendedores auto motivados que cuestionen las normas establecidas y satisfagan sus metas personales a través de su propia acción.

Castillo y Orlando (2008), mencionan que la Universidad como institución debe orientar a la formación de individuos que desarrollen comportamientos y competencias emprendedoras, así mismo, debe fomentar el espíritu emprendedor y 
empresarial, la deseabilidad de ser empresario y formar técnicamente para optimizar la visión de crear y consolidar nuevas empresas. Porque el espíritu emprendedor, según (Martín, Hernangómez y Rodríguez, 2005), interviene de manera preponderante en la innovación y el bienestar de una economía.

Es cada vez mayor el consenso que existe en el rol de la Universidad como formadora de emprendedores (Krauss, 2008). Sin embargo, la forma de cómo desde la Universidad se debe impulsar este espíritu, es aún una materia insuficientemente tratada (Martín, Hernangómez y Rodríguez, 2005). Así, la Universidad no debe quedarse pasiva, debe participar de manera activa en el estudio de las problemáticas que aquejan a la sociedad, debe proponer ideas y acciones, intercambiar información, movilizar a la sociedad y debe tener la responsabilidad de favorecer la puesta en marcha de esas acciones.

En la última década, la vinculación que tiene la Universidad con la sociedad, principalmente con el sector productivo, ha sido una de las acciones más deseadas por las universidades. Se han realizado "cientos, si no es que miles", de convenios, se han establecido estructuras administrativas específicas para el desarrollo de esas actividades, así como también se han efectuado foros y debates. Sin embargo el balance ha sido negativo (Campos y Sánchez, 2005).

Las universidades en su actuar como generadores de formación deben tener la visión para adelantarse a las transformaciones sociales para poderles dar respuesta ante las exigencias que se dan en un entorno sumamente dinámico y exigente. Uno de los indicadores de calidad en los cuales se refleja el actuar de las universidades, se compone de la capacidad para preparar su oferta de graduados y su formación a las demandas del mercado laboral actual (Unesco, 1999).

Lo anterior sugiere extender la base de acción tradicional de las universidades y fomentar en los estudiantes el desarrollo de las competencias que los faculte para ingresar de manera satisfactoria y competente al entorno laboral o que él mismo sea capaz de crear empleos. Estas competencias se deben integrar a la adquisición del saber, del saber-hacer, y del saber vivir juntos. "Los sistemas educativos deben centrar su actividad en el desarrollo de determinadas cualidades personales y en las llamadas destrezas blandas dirigidas a la integración y a la adaptabilidad al cambio" (Álvarez y Moreno, 2002). Por lo tanto, con base en estrategias y técnicas novedosas de enseñanza se contará con mejores escenarios que los actuales para desarrollar las competencias emprendedoras de los estudiantes, promovidas desde sus profesores para lograr una cultura emprendedora.

\section{Competencias emprendedoras (Espíritu emprendedor)}

Mucho se ha escrito acerca de las competencias, y por lo tanto se han desarrollado múltiples conceptos acerca de lo que son. Autores tales como (Tejada, 1999; Lévy-Leboyer, 2003; Zabalza, 2007; Rychen y Salganik, 2006; Barrera, 2007), se han dedicado (aunque no de manera exclusiva) al estudio de las mismas (Martínez y Carmona, 2009). 
Este tema se ha estudiado desde el punto de vista empresarial y social, pero también desde el punto de vista educativo. Precisamente, desde esta perspectiva se han desarrollado diferentes conceptos acerca de lo que es una competencia. Para el Proyecto Tuning para América Latina (2007), las competencias, "son las capacidades que todos los seres humanos necesitan para resolver, de manera eficaz y autónoma las situaciones de la vida". Para Bellocchio (2010) las competencias "integran conocimientos, habilidades, actitudes y valores que se movilizan en un contexto determinado".

Autores como Tejada (1999), Pereda y Berrocal (2001), Lévy-Leboyer (2003) y Escobar (2005), entre otros, clasifican las competencias en genéricas y específicas. Las primeras se refieren a las competencias que toda persona debe tener para poder desenvolverse en cualquier área de trabajo o de estudio. El proyecto DeSeCo (2003) describe las competencias de la siguiente manera "Involucra la habilidad de enfrentar demandas complejas, apoyándose en y movilizando recursos psicosociales (incluyendo destrezas y actitudes) en un contexto en particular".

El Proyecto Tuning (2003) clasifica las competencias en 3 grandes grupos:

a) Instrumentales, que son las herramientas para el aprendizaje y la formación tales como: comunicación verbal, tipos de pensamiento, manejo de idiomas, entre otras.

b) Interpersonales, que son las que permiten mantener una buena relación social con los demás tales como: trabajo en equipo, sentido ético, adaptación al entorno diversidad y multiculturalidad, entre otros.

c) Sistémicas, relacionadas con la visión de conjunto y la capacidad de gestionar adecuadamente la totalidad de la actuación, tales como creatividad, capacidad innovadora, gestión de proyectos, orientación al logro, espíritu emprendedor, entre otras.

Asimismo, la Comisión Europea en el texto Competencias Clave para un Aprendizaje a lo largo de la vida (2004) define las competencias clave como aquellas que son necesarias para el desarrollo personal a lo largo de la vida, siendo éstas multifuncionales y transferibles, lo que quiere decir que son aplicables en muchos contextos y situaciones, así como también sirven para resolver diferentes problemas o para llevar a cabo diferentes tareas. En el mismo texto se reconocen ocho competencias clave entre las se encuentra el espíritu emprendedor, el cual lo definen como:

La capacidad para provocar cambios y la habilidad para aceptar y apoyar cambios producidos por factores externos. El espíritu emprendedor incluye la aceptación del cambio, asumiendo la responsabilidad de las propias 
acciones (positivas o negativas) marcando objetivos y alcanzándolos y teniendo motivación para lograr el éxito.

Sobrado y Fernández (2010), Martínez y Carmona (2009), hacen alusión a las diferentes concepciones que diversos autores han hecho de las competencias, tomando en cuenta la variación que éstas tienen con base en los diferentes enfoques y las disciplinas que las abordan. Sin embargo encuentran puntos de unión y características comunes entre ellos, lo que da resultado a su concepto de competencias emprendedoras, abordando las competencias desde una perspectiva holística, conjuntando los enfoques educativo, economicista y social.

Tomando en cuenta lo antes mencionado, podemos observar la importancia que las competencias tienen en los individuos para su desarrollo personal y laboral. Si lo que pretendemos es el desarrollo de competencias en los estudiantes, debemos tener en cuenta el perfil que éstos tienen y ver la relación que existe con las variables a estudiar.

\section{Cultura emprendedora}

La cultura emprendedora implica la edificación comportamientos individuales afines a las acciones colectivas que simbolicen la construcción de tareas innovadoras que generen bienes y servicios con un sentido lucrativo o no. La cultura emprendedora presenta una "doble faceta". Por un lado, la de generar nuevos proyectos con "autonomía, capacidad de asumir riesgo, con responsabilidad, con intuición, con capacidad de proyección al exterior y con capacidad de reaccionar y resolver los problemas". Por otro lado, "también supone saber llevar a cabo proyectos de otros con el mismo espíritu de innovación, responsabilidad y autonomía" (Gutiérrez, 2006).

Cabellos (2006), se refiere al emprendedor universitario, como un individuo con capacidades superiores y amplios conocimientos, el cual que está motivado para comenzar y desarrollar sus sueños proactiva, asertiva e innovadoramente, asertiva y proactiva en los diversos escenarios y sectores económicos o sociales, y que cuenten con las competencias que lo identifiquen como un individuo especial, elegido por sus propias características a ser eficiente y sobresalir de los demás, llevándolo a producir impactos en la rama productiva que le seduzca.

\section{MATERIALES Y MÉTODOS}

Para instrumentar la hipótesis, se decidió aplicar el cuestionario a estudiantes matriculados desde el primero hasta el último curso de las áreas Contable y de Administración de Empresas. Para una población muestral total de 773 estudiantes se empleó el esquema de muestreo aleatorio simple de proporciones, con error del 
$3 \%$, arrojando un total de 315 encuestas que se aplicaron de manera proporcional a hombres y mujeres de los matriculados en ambas carreras.

Se consideraron aspectos sociales asociadas al género (masculino y femenino), la edad, el programa de estudios (Contador o Licenciado en Administración) y año que cursa el estudiante. Para el resto de las preguntas que comprenden las variables dependiente e independiente fueron de tipo Likert, donde 1 significa estoy completamente en desacuerdo, hasta $5=$ estoy completamente de acuerdo, habiéndose estructurado el cuestionario tal y como se muestra en la siguiente tabla

Por lo que respecta a los métodos estadísticos empleados, básicamente se realizaron comparaciones de promedios basados en análisis de varianza (ANOVA) y análisis de componentes principales (ACP) a los indicadores de las variables cuyos indicadores se basan en un intervalo de preferencia o escala Likert. El ACP se empleó para obtener los factores de regresión que se incluyeron como variables exógenas en modelos de regresión no lineales (siguiendo la lógica de Paswan, Santarriaga Pineda y Soto Ramírez (2010) y Carter y Van Auken 2005), como los probit y logit ordenados.

Tabla 1. Estadística básica y propiedades de los indicadores del cuestionario.

\begin{tabular}{|c|c|c|c|c|c|c|}
\hline Variable & Indicadores y clave & Propiedad & Media & DE & Mín. & Máx. \\
\hline \multirow{4}{*}{ Sociales } & Edad & Medición & 20.48 & 1.87 & 17 & 28 \\
\hline & Género (masculino, femenino) & Dummy & 0.46 & 0.50 & 0 & 1 \\
\hline & $\begin{array}{lll}\text { Carrera (Contador, } & \text { Licenciado } & \text { en } \\
\text { Administración) } & \end{array}$ & Medición & 0.50 & 0.50 & 0 & 1 \\
\hline & Curso (de $1^{\circ}$. a $\left.5^{\circ}\right)$ & Medición & 4.82 & 2.86 & 1 & 9 \\
\hline \multirow{5}{*}{$\begin{array}{l}\text { Experiencia } \\
\text { emprendedora y } \\
\text { laboral }\end{array}$} & $\begin{array}{l}\text { Un miembro o más de mi familia es o ha sido } \\
\text { propietario de una empresa, EE1 }\end{array}$ & \multirow{5}{*}{$\begin{array}{l}\text { Dummy, } \\
1=\mathrm{Si} \\
2=\mathrm{No}\end{array}$} & 1.54 & 0.50 & 1 & 2 \\
\hline & $\begin{array}{l}\text { Tengo amigos que actualmente son dueños de } \\
\text { una empresa, EE2 }\end{array}$ & & 1.38 & 0.49 & 1 & 2 \\
\hline & $\begin{array}{l}\text { He trabajado en pequeñas empresas en contacto } \\
\text { cercano con el dueño, EE3 }\end{array}$ & & 1.39 & 0.49 & 1 & 2 \\
\hline & $\begin{array}{l}\text { He trabajado en medianas o grandes empresas en } \\
\text { contacto cercano con el dueño, EE4 }\end{array}$ & & 1.71 & 0.45 & 1 & 2 \\
\hline & $\begin{array}{l}\text { Tengo experiencia en áreas funcionales de alguna } \\
\text { empresa, EE5 }\end{array}$ & & 1.46 & 0.50 & 1 & 2 \\
\hline \multirow{6}{*}{$\begin{array}{l}\text { Formación } \\
\text { escolar o del plan } \\
\text { de la carrera }\end{array}$} & $\begin{array}{l}\text { En las materias del plan de estudios de mi carrera } \\
\text { se incluyen temas de liderazgo, FE1 }\end{array}$ & \multirow{6}{*}{$\begin{array}{l}\text { Intervalo de } \\
\text { preferencia } \\
\text { del } 1-5\end{array}$} & 3.16 & 1.17 & 1 & 5 \\
\hline & $\begin{array}{l}\text { En las materias del plan de estudios de mi carrera } \\
\text { se fomenta la creatividad, FE2 }\end{array}$ & & 3.19 & 1.10 & 1 & 5 \\
\hline & $\begin{array}{l}\text { En las materias del plan de estudios de mi carrera } \\
\text { se fomenta la innovación, FE3 }\end{array}$ & & 3.31 & 1.03 & 1 & 5 \\
\hline & $\begin{array}{l}\text { En las materias del plan de estudios de mi carrera } \\
\text { se incluyen temas o actividades sobre análisis del } \\
\text { entorno e identificación de oportunidades, FE4 }\end{array}$ & & 3.41 & 1.03 & 1 & 5 \\
\hline & $\begin{array}{l}\text { Las materias del plan de estudios de mi carrera } \\
\text { existen actividades sobre asunción de riesgos, } \\
\text { FE5 }\end{array}$ & & 3.08 & 0.99 & 1 & 5 \\
\hline & $\begin{array}{l}\text { Tengo materias donde se analiza la tolerancia a } \\
\text { los cambios, FE6 }\end{array}$ & & 3.11 & 1.07 & 1 & 5 \\
\hline
\end{tabular}




\begin{tabular}{|c|c|c|c|c|c|c|}
\hline & $\begin{array}{l}\text { En mi carrera se fomenta la creación de } \\
\text { empresas, FE7 }\end{array}$ & & 3.75 & 1.11 & 1 & 5 \\
\hline \multirow{12}{*}{$\begin{array}{l}\text { Percepción } \\
\text { propia como } \\
\text { emprendedor }\end{array}$} & Tengo alto nivel de energía y entusiasmo, PE1 & \multirow{12}{*}{$\begin{array}{l}\text { Intervalo de } \\
\text { preferencia } \\
\text { del } 1-5\end{array}$} & 4.14 & 0.89 & 1 & 5 \\
\hline & Tengo confianza en mí mismo, PE2 & & 4.28 & 0.91 & 1 & 5 \\
\hline & $\begin{array}{l}\text { Establezco objetivos a largo plazo y me sujeto a } \\
\text { ellos, PE3 }\end{array}$ & & 3.97 & 0.87 & 1 & 5 \\
\hline & Me gusta resolver problemas diferentes, PE4 & & 4.06 & 0.89 & 1 & 5 \\
\hline & $\begin{array}{l}\text { Me gusta tomar la iniciativa y me hago } \\
\text { responsable del éxito o fracaso, PE5 }\end{array}$ & & 4.12 & 0.94 & 1 & 5 \\
\hline & Soy creativo e innovador, PE6 & & 3.86 & 0.99 & 1 & 5 \\
\hline & $\begin{array}{l}\text { Obtengo suficiente información antes de tomar } \\
\text { un decisión, PE7 }\end{array}$ & & 3.91 & 0.88 & 1 & 5 \\
\hline & Disfruto adquiriendo responsabilidades, PE8 & & 3.94 & 0.92 & 1 & 5 \\
\hline & Me gusta asumir riesgos, PE9 & & 3.87 & 0.92 & 1 & 5 \\
\hline & Me gusta triunfar por mis propios méritos, PE10 & & 4.48 & 0.85 & 1 & 5 \\
\hline & Tengo un fuerte deseo de independencia, PE11 & & 4.26 & 0.97 & 1 & 5 \\
\hline & $\begin{array}{l}\text { Prefiero crear mi propia empresa que ser } \\
\text { empleado, PE12 }\end{array}$ & & 4.39 & 0.96 & 1 & 5 \\
\hline \multirow{8}{*}{$\begin{array}{l}\text { Rol o influencia } \\
\text { del docente en la } \\
\text { promoción de } \\
\text { emprende- } \\
\text { durismo }\end{array}$} & $\begin{array}{l}\text { Los docentes utilizan estrategias educativas que } \\
\text { fomentan la creatividad, RD1 }\end{array}$ & \multirow{8}{*}{$\begin{array}{l}\text { Intervalo de } \\
\text { preferencia } \\
\text { del } 1-5\end{array}$} & 3.23 & 0.97 & 1 & 5 \\
\hline & $\begin{array}{l}\text { Los docentes utilizan estrategias educativas que } \\
\text { fomentan la innovación, RD2 }\end{array}$ & & 3.23 & 0.97 & 1 & 5 \\
\hline & $\begin{array}{l}\text { Los docentes utilizan estrategias educativas que } \\
\text { fomentan el trabajo en equipo, RD3 }\end{array}$ & & 3.99 & 0.86 & 1 & 5 \\
\hline & Los docentes promueven el liderazgo, RD4 & & 3.52 & 0.95 & 1 & 5 \\
\hline & $\begin{array}{l}\text { Los docentes promueven el espíritu empresarial, } \\
\text { RD5 }\end{array}$ & & 3.59 & 1.04 & 1 & 5 \\
\hline & $\begin{array}{l}\text { Los docentes promueven desarrollo de proyectos } \\
\text { emprendedores, RD6 }\end{array}$ & & 3.63 & 1.01 & 1 & 5 \\
\hline & $\begin{array}{lccc}\text { Los } & \text { docentes } & \text { emplean } & \text { simuladores } \\
\text { empresariales, RD7 } & & \\
\end{array}$ & & 3.35 & 1.17 & 1 & 5 \\
\hline & $\begin{array}{l}\text { La mayoría de los docentes tienen experiencia } \\
\text { como dueño o socio de una empresa, RD8 }\end{array}$ & & 3.17 & 1.12 & 1 & 5 \\
\hline
\end{tabular}

Fuente: Elaboración propia.

Los modelos logit o probit ordenados, tienen como variable exógena $-\mathrm{y}^{*}-\mathrm{a}$ una variable latente (que solo se observa cuando cruza un umbral o límites), cuyos niveles son afectados por variables explicativas, de la forma:

$$
\mathbf{y}^{*_{i}}=\mathbf{X}_{\mathbf{i}}{ }^{\prime} \boldsymbol{\beta}+\mathbf{u}_{\mathrm{i}} ; \text { (1) }
$$

Donde $\mathbf{X}_{\mathbf{i}}$ es una matriz de variables explicativas, $\boldsymbol{\beta}$ es un vector de parámetros, $\mathbf{u}_{\mathbf{i}}$ es un vector de errores estocásticos, $\mathbf{y}^{\boldsymbol{*}_{\mathbf{i}}}$ es la variable dependiente no observada, pero cercanamente relacionada con $\mathbf{y}_{i}$; siendo esta última observable. La relación entre $\mathbf{y}_{\mathbf{i}} \quad \mathbf{y}_{\mathbf{i}}$ se supone sea una función de puntos limite $\left(\boldsymbol{\mu}_{\mathbf{j}}\right)$, que son estimados junto con los coeficientes de regresión y varían con cada individuo. Para el caso que nos ocupa, los valores de la variable observada $-\mathbf{y}$ - están asociados con el número de eventos o experiencia emprendedora o de empleo que indicaron los estudiantes encuestados. 


$$
y=\left\{\begin{array}{ccc}
3 & (4 \text { o } 5 \text { eventos }) & \text { Si } \mathbf{y}_{\mathbf{i}}>\boldsymbol{\mu}_{\mathbf{2}} \\
2 & (2 \text { o } 3 \text { eventos }) & \text { Si } \boldsymbol{\mu}_{\mathbf{1}}<\mathbf{y}_{\mathbf{i}} \leq \boldsymbol{\mu}_{\mathbf{2}} \\
1 & (1 \text { o ningún evento }) & \text { Si } \mathbf{y}_{\mathbf{i}} \leq \boldsymbol{\mu}_{\mathbf{1}}
\end{array}\right.
$$

Donde $\mu_{1}{ }^{\wedge} \mu_{2}\left(0<\mu_{1}<\mu_{2}\right)$ son los puntos limite desconocidos de $\mathbf{y}^{*}$ que son estimados junto con los parámetros $\beta$. Las probabilidades individuales para cada valor que toma la variable dependiente observada $-\mathbf{y}_{\mathbf{i}}-$ son:

$$
\begin{aligned}
& \mathrm{p}\left(\mathrm{y}_{\mathrm{i}}=1\right)=\mathrm{p}\left(\mathrm{y}_{\mathrm{i}} \leq \mu_{1}\right)=\mathrm{F}\left(\mu_{1}-\mathrm{X}_{\mathrm{i}}^{\prime} \beta\right) \\
& \mathrm{p}\left(\mathrm{y}_{\mathrm{i}}=2\right)=\mathrm{p}\left(\mu_{1}<\mathrm{y}_{\mathrm{i}} \leq \mu_{2}\right)=\mathrm{F}\left(\mu_{2}-\mathrm{X}_{\mathrm{i}}^{\prime} \beta\right)-\mathrm{F}\left(\mu_{1}-\mathrm{X}_{\mathrm{i}}^{\prime} \beta\right) \\
& \mathrm{p}\left(\mathrm{y}_{\mathrm{i}}=3\right)=\mathrm{p}\left(\mathrm{y}_{\mathrm{i}}>\mu_{2}\right)=1-\mathrm{F}\left(\mu_{2}-\mathrm{X}_{\mathrm{i}}{ }^{\prime} \beta\right)
\end{aligned}
$$

La probabilidad de que la observación (individuo) $i$ seleccione o "caiga" en la opción $j$ es:

$$
p_{i j}=p\left(y_{i}=j\right)=p\left(\mu_{j-1}<y_{i} \leq \mu_{j}\right)=F\left(\mu_{j}-X_{i}^{\prime} \beta\right)-F\left(\mu_{j-1}-X_{i}^{\prime} \beta\right)
$$

Para el modelo logístico ordenado, $\mathrm{F}$ es la función de densidad acumulada logística, esto es $\mathrm{F}\left(\mathrm{X}_{\mathrm{i}}^{\prime} \beta\right)=\exp \left(\mathrm{X}_{\mathrm{i}}^{\prime} \beta\right) /\left(1+\exp \left(\mathrm{X}_{\mathrm{i}}{ }^{\prime} \beta\right)\right)$. Donde se supone que los errores aleatorios $\left(\mathrm{u}_{\mathrm{i}}\right)$ siguen una distribución logística.

Para el modelo probit ordenado, $\mathrm{F}$ es la función de densidad acumulada normal, esto es $\mathrm{F}\left(\mathrm{X}_{\mathrm{i}}^{\prime} \beta\right)=\Phi\left(\mathrm{X}_{\mathrm{i}}^{\prime} \beta\right)=\int_{-\infty}^{X \prime \beta} \phi(z) d z$. Donde se supone que los errores estocásticos se distribuyen como una variable normal estándar, esto es $\mathrm{u}_{\mathrm{i}} \sim \mathrm{N}(0,1)$.

Los parámetros son obtenidos al maximizar la función log - verosimilitud empleando métodos numéricos. Para esto, de acuerdo con Jackman (2000) y considerando el ejemplo del modelo probit se tiene:

$$
\ln \mathcal{L}=\sum_{i=1}^{N} \sum_{i=0}^{M} Z_{i j} \ln \left(\Phi_{i j}-\Phi_{i, j-1}\right)
$$

Donde se define a $\mathrm{Zij}$ como una variable indicador, con valores de 1 si $\mathrm{y}_{\mathrm{i}}=\mathrm{j}$, o 0 de otra manera. Además, $\Phi_{\mathrm{ij}}=\Phi\left(\mu_{\mathrm{j}}-\mathrm{X}_{\mathrm{i}}^{\prime} \beta\right)$ y $\Phi_{\mathrm{i}, \mathrm{j}-1}=\Phi\left(\mu_{\mathrm{j}-1}-\mathrm{X}_{\mathrm{i}}^{\prime} \beta\right)$. Al agregar restricciones a $\mu$ y $\beta$ ("anclarlos" en algún valor), se obtiene los estimadores de máxima verosimilitud: $\left(\hat{\beta}, \hat{\mu}_{1}, \hat{\mu}_{2}\right)$

La interpretación de los coeficientes no es directa, debido a que se trata de modelos de regresión no lineales, por lo que el signo de los coeficientes y su significancia estadística solo indican la dirección de la respuesta asociada con la presencia o nivel de una variable particular. En este sentido, cobra importancia la estimación de los efectos marginales; que se definen como el efecto marginal de un 
incremento en el regresor $\mathrm{x}_{\mathrm{r}}$ en la probabilidad de seleccionar $\mathrm{j}$; $\mathrm{y}$ se calculan de la siguiente manera:

$\frac{\partial p_{i j}}{\partial x_{r i}}=\left\{F^{\prime}\left(\mu_{j-1}-x_{i}^{\prime} \beta\right)-F^{\prime}\left(\mu_{j}-x_{i}^{\prime} \beta\right)\right\} \beta_{r}$

Donde $\partial \mathrm{p}(\cdot) / \partial \mathrm{x}_{\mathrm{ri}}$ es la derivada parcial de la probabilidad con respecto a $\mathrm{x}_{\mathrm{r}}(\mathrm{y}$ manteniendo los otros regresores como constantes); $\beta_{\mathrm{r}}$ es el estimador máximo verosimilitud de $\mathrm{x}_{\mathrm{r}}$. Los efectos marginales de cada variable o regresor suman cero a lo largo de las categorías o alternativas j. Su interpretación es sencilla, un incremento unitario en la variable independiente (o regresor) incrementa o decrementa la probabilidad de seleccionar la alternativa $\mathrm{j}$, por el efecto marginal expresado en porcentaje. Se empleó el programa y rutinas de STATA para el cálculo de los estimadores de máximo verosimilitud probit y logit ordenados, así como de los efectos marginales. Finalmente se empleó la prueba brant ${ }^{1}$ de Stata, para evaluar el supuesto de regresión paralela (también llamado supuesto proporcional de probabilidades) después de realizar la regresión logística, de acuerdo con Williams (2006). Esta prueba permite confirmar, si se mantiene el supuesto, que el modelo logit ordenado fue adecuado para modelar este conjunto de datos.

\section{RESULTADOS}

Comparación de promedios. La comparación de promedios se realiza con Análisis de Varianza; de este modo se prueba si existen diferencias significativas entre las percepciones que tienen los estudiantes entrevistados, clasificando a estos por género (masculino, femenino), por la carrera (Contable o Licenciado en Administración) y por la experiencia empresarial o de trabajo (baja, media y alta). Las frecuencias de esta variable se observan en la tabla 2. Como se puede apreciar, los extremos son $10 \%$ menores que el punto medio.

Tabla 2. Frecuencias para la variable dependiente

\begin{tabular}{|l|c|c|c|c|}
\hline $\begin{array}{c}\text { Experiencia } \\
\text { empresarial }\end{array}$ & $\begin{array}{c}\text { Código para } \\
\text { la alternativa }\end{array}$ & Definición & Frecuencia & Porcentaje \\
\hline Alto & 3 & 4 o 5 eventos & 92 & 29.2 \\
\hline Medio & 2 & 2 o 3 eventos & 134 & 42.5 \\
\hline Bajo & 1 & 1 o ningún evento & 89 & 28.3 \\
\hline Total & & & 315 & Total \\
\hline
\end{tabular}

\footnotetext{
${ }^{1}$ La prueba compara las pendientes de los coeficientes de $\mathrm{j}-1$ modelos logísticos binarios implicados en el modelo logístico ordenado. Stata reporta los resultados de una prueba general de todo el modelo y pruebas del supuesto para cada variable independiente (regresor) en el modelo.
} 
Fuente: Elaboración propia con resultados de 315 encuestas.

Posteriormente y como se observa en la siguiente tabla número 3, las mujeres son más críticas que los hombres en el papel que juegan las materias del plan de estudio. De manera similar, los estudiantes de Contabilidad son más críticos que los de Licenciado en Administración; dado que en ambos caso evalúan 2 de estos indicadores por abajo del promedio (aunque estos indicadores son diferentes en cada caso). Al considerarse la experiencia empresarial, los estudiantes que tienen poca experiencia son los más críticos. Por otra parte, casi todos los estudiantes (independientemente del género, carrera, etc.) opinan que en lo que más están de acuerdo es que en la "carrera se fomenta la creación de empresas". En este sentido, los estudiantes están calificando al papel de las clases con poco impacto al fomento de la empresarialidad.

Las opiniones son más divergentes al tratarse de los indicadores del perfil del emprendedor. En cuanto a género, la mujer tiene menos confianza en sí misma como creativa e innovadora o en cuanto a asumir riesgos, o para la toma de decisiones basada en información. El hombre se autocalificó por abajo del promedio en 2 aspectos: como creativo o innovador y al tomar responsabilidades. La mujer se autocalifica por arriba del promedio en 2 indicadores, uno de ellos es querer triunfar por méritos propios (donde coincide con el hombre); y el otro al querer establecer su propia empresa. 
Tabla 3. Comparación de promedios por diferentes características

\begin{tabular}{|c|c|c|c|c|c|c|c|c|c|c|c|c|c|c|c|}
\hline \multirow{2}{*}{ Variable } & \multirow{2}{*}{$\begin{array}{l}\text { Indicador } \\
\text { por clave }\end{array}$} & \multicolumn{4}{|c|}{ Género } & \multicolumn{4}{|c|}{ Carrera } & \multicolumn{6}{|c|}{ Experiencia empresarial } \\
\hline & & \multicolumn{2}{|l|}{ Hombre } & \multicolumn{2}{|l|}{ Mujer } & \multicolumn{2}{|l|}{ Contador } & \multicolumn{2}{|l|}{ L. Admon. } & \multicolumn{2}{|l|}{ Bajo } & \multicolumn{2}{|l|}{ Medio } & \multicolumn{2}{|l|}{ Alto } \\
\hline \multirow{8}{*}{$\begin{array}{l}\text { Formación } \\
\text { escolar o del } \\
\text { plan de la } \\
\text { carrera }\end{array}$} & FE1 & 3.03 & & 3.26 & & 3.10 & $* *$ & 3.03 & $* *$ & 3.25 & & 3.14 & & 3.10 & \\
\hline & FE2 & 3.14 & & 3.24 & & 3.11 & $* *$ & 3.18 & & 3.29 & & 3.22 & & 3.04 & \\
\hline & FE3 & 3.26 & & 3.36 & & 3.20 & & 3.32 & & 3.45 & & 3.27 & & 3.25 & \\
\hline & FE4 & 3.39 & & 3.43 & & 3.29 & & 3.38 & & 3.55 & & 3.47 & & 3.20 & \\
\hline & FE5 & 3.10 & & 3.07 & $* *$ & 3.31 & & 3.06 & & 3.04 & $* *$ & 3.16 & & 3.01 & \\
\hline & FE6 & 3.16 & & 3.07 & $* *$ & 3.31 & $* *$ & 3.13 & & 3.16 & & 3.17 & & 2.98 & \\
\hline & FE7 & 3.72 & $* *$ & 3.78 & $* *$ & 3.45 & & 3.80 & $* *$ & 3.80 & $* *$ & 3.76 & $* *$ & 3.68 & $* *$ \\
\hline & Promedio & 3.26 & & 3.32 & & 3.69 & & 3.27 & & 3.36 & & 3.31 & & 3.18 & \\
\hline \multirow{13}{*}{$\begin{array}{l}\text { Percepción } \\
\text { propia como } \\
\text { emprendedor }\end{array}$} & PE1 & 4.23 & & 4.06 & & 4.11 & & 4.17 & & 4.25 & & 4.05 & & 4.16 & \\
\hline & PE2 & 4.42 & & 4.16 & & 4.23 & & 4.33 & & 4.19 & & 4.28 & & 4.37 & \\
\hline & PE3 & 3.99 & & 3.94 & & 3.97 & & 3.96 & & 3.94 & & 3.94 & & 4.02 & \\
\hline & PE4 & 4.20 & & 3.94 & & 4.05 & & 4.06 & & 4.03 & & 4.03 & & 4.12 & \\
\hline & PE5 & 4.30 & & 3.96 & & 4.11 & & 4.13 & & 3.98 & & 4.07 & & 4.33 & \\
\hline & PE6 & 3.97 & $* *$ & 3.76 & $* *$ & 3.75 & $* *$ & 3.96 & & 3.66 & $* *$ & 3.83 & & 4.09 & \\
\hline & PE7 & 4.06 & & 3.79 & $* *$ & 3.85 & & 3.97 & & 3.90 & & 3.88 & & 3.98 & \\
\hline & PE8 & 3.97 & $* *$ & 3.92 & & 3.99 & & 3.90 & & 3.85 & & 3.87 & & 4.13 & \\
\hline & PE9 & 4.01 & & 3.75 & $* *$ & 3.87 & & 3.87 & $* *$ & 3.69 & $* *$ & 3.80 & $* *$ & 4.16 & \\
\hline & PE10 & 4.53 & $* *$ & 4.44 & $* *$ & 4.48 & $* *$ & 4.47 & $* *$ & 4.48 & $* *$ & 4.44 & $* *$ & 4.53 & $* *$ \\
\hline & PE11 & 4.34 & & 4.19 & & 4.20 & & 4.33 & & 4.19 & & 4.29 & & 4.29 & \\
\hline & PE12 & 4.39 & & 4.39 & $* *$ & 4.45 & $* *$ & 4.34 & & 4.44 & $* *$ & 4.37 & $* *$ & 4.37 & \\
\hline & Promedio & 4.20 & & 4.03 & & 4.09 & & 4.12 & & 4.05 & & 4.07 & & 4.21 & \\
\hline \multirow{9}{*}{$\begin{array}{l}\text { Rol o } \\
\text { influencia del } \\
\text { docente en la } \\
\text { promoción de } \\
\text { emprende- } \\
\text { durismo }\end{array}$} & RD1 & 3.19 & $* *$ & 3.27 & & 3.26 & $* *$ & 3.21 & $* *$ & 3.29 & & 3.26 & & 3.14 & \\
\hline & RD2 & 3.19 & $* *$ & 3.28 & & 3.25 & $* *$ & 3.22 & $* *$ & 3.33 & & 3.21 & & 3.18 & \\
\hline & RD3 & 4.06 & $* *$ & 3.94 & $* *$ & 3.94 & $* *$ & 4.04 & $* *$ & 4.16 & $* *$ & 3.86 & $* *$ & 4.02 & $* *$ \\
\hline & RD4 & 3.51 & & 3.54 & & 3.57 & & 3.48 & & 3.66 & & 3.44 & & 3.51 & \\
\hline & RD5 & 3.59 & & 3.59 & & 3.59 & & 3.59 & & 3.80 & & 3.47 & & 3.57 & \\
\hline & RD6 & 3.59 & & 3.66 & & 3.52 & & 3.73 & $* *$ & 3.71 & & 3.60 & & 3.60 & \\
\hline & RD7 & 3.31 & & 3.38 & & 3.32 & & 3.37 & & 3.40 & & 3.34 & & 3.32 & \\
\hline & RD8 & 3.10 & $* *$ & 3.23 & $* *$ & 3.29 & & 3.04 & $* *$ & 3.25 & $* *$ & 3.18 & & 3.08 & $* *$ \\
\hline & Promedio & 3.44 & & 3.48 & & 3.47 & & 3.46 & & 3.57 & & 3.42 & & 3.43 & \\
\hline
\end{tabular}

Fuente: Elaboración propia

Notas: Al entrevistado respondió en esta escala: 1 "Muy en desacuerdo" y 5 la más alta con "Muy de acuerdo". 2/ La comparación de los promedios se realizó con Análisis de Varianza, donde los dos asteriscos (**) denotan que estos valores están al 95\% de significancia por abajo o por arriba del promedio.

Por carrera, los estudiante del área contable tienen un indicador por abajo del promedio (creatividad e innovación) y 2 por arriba (triunfar por méritos propios y crear empresa propia); mientras que los administradores presentan uno por arriba (triunfar por méritos propios) y otro por abajo (no querer asumir riesgos). En este sentido puede decirse que los contadores presentan una auto calificación más alta en su perfil emprendedor (Tabla 3).

Los estudiantes con menor experiencia emprenderora, presentan 2 indicadores por abajo del promedio y 2 por arriba; los de experiencia intermedia uno por abajo y 2 por arriba, finalmente, los estudiantes con mayor experiencia emprendedora solo tienen un indicador por arriba del promedio. En este sentido, los de menos experiencia tienen una visión de menor confianza en sí mismos; y conforme aumenta su auto confianza coincide con una mayor experiencia empresarial/laboral.

Independientemente de las clasificaciones hechas a los estudiantes, el indicador más bajo es el de una persona creativa e innovadora; el no querer asumir riesgos. Por otra parte, el querer triunfar por méritos propios y desear establecer su propia empresa son los indicadores por arriba del promedio. 
En cuanto al papel o rol que tienen los profesores al fomento de la cultura emprendedora; los hombres son más críticos, dado que califican a 3 indicadores por abajo del promedio (en fomentar la creatividad, la innovación o que crean que los profesores tienen negocios propios). En esta apreciación coinciden también con los contadores y los administradores.

Prácticamente todos los estudiantes, independientemente de cómo fueron agrupados, coinciden en que los docentes fomentan trabajo en equipo (indicador que está por arriba del promedio) y que los docentes no tienen experiencia en negocios propios (indicador por abajo del promedio).

Finalmente, debe decirse que los promedio generales del rol del docente y las materias del plan de estudios están por debajo del promedio del perfil emprendedor del estudiante. En este sentido, los estudiantes son más críticos de su entorno académico que auto críticos.

\section{Análisis de componentes principales $(A C P)$}

Con el ACP se busca definir, a partir de un conjunto de variables originales estrechamente relacionadas entre sí, a otras variables "intrínsecas" que sinteticen a estas variables originales; esto se hace con un costo en la pérdida de información. En la tabla 4, se presentan los resultados.

Se consideran los resultados de los componentes rotados, donde claramente se observa la definición de 3 componentes, asociados al perfil emprendedor de los estudiantes, al rol de los docentes y a la formación escolar en la promoción de la cultura emprendedora. Debe decirse que al extraer 3 componentes se pierde una cantidad importante de información, dado que solo se preserva el 54\% de la varianza. Los componentes principales no rotados no definen claramente estas variables intrínsecas, y también pierden mucha de la información. Estos componentes serán empleados, en particular sus factores de regresión asociados (y que no se presentan aquí) para el análisis de regresión, que posteriormente se muestra.

\section{Modelo de regresión ordenado logit y probit}

Se propone el siguiente modelo ${ }^{2}$ :

$\mathrm{Y}_{\mathrm{i}}=\mathrm{B} 0+\mathrm{B} 1+\mathrm{B} 2 \mathrm{Edad}+\mathrm{B} 3 \mathrm{Carr}_{\mathrm{i}}+\mathrm{B} 4 \mathrm{Gen}_{\mathrm{i}}+\mathrm{B} \mathrm{PE}_{\mathrm{i}}+\mathrm{B} 6 \mathrm{RD}_{\mathrm{i}}+\mathrm{B} 7 \mathrm{FE}_{\mathrm{i}}+\mathrm{e}_{\mathrm{i}}$

Donde:

$\mathrm{Y}=$ Experiencia emprendedora o laboral, y puede tomar los siguientes valores, $1=$ alta (4 o 5 eventos), $2=$ Media ( 2 o 3 eventos $)$ y $3=$ Baja o nula ( 1 o ningún evento). $\mathrm{B} 0$ y B2 $=$ son los interceptos.

Edad $=$ Edad del entrevistado.

\footnotetext{
${ }^{2}$ En un primer modelo se incluyó también el semestre en el que cursa, pero no resulto significativo en términos estadísticos. Al eliminar esta variable del modelo, mejoraron los resultados estadísticos en el resto de los estimadores (betas asociadas a las otras variables), por lo que se decidió proponer este modelo reducido.
} 
Tabla 4. ACP para variables de percepción de entorno emprendedor

\begin{tabular}{|c|c|c|c|c|c|c|}
\hline & \multicolumn{3}{|c|}{ Componentes no rotados } & \multicolumn{3}{|c|}{ Componentes rotados } \\
\hline & CPNR1 & CPNR2 & CPNR3 & PerfEmp & Roldocent & FormEsc \\
\hline $\begin{array}{l}\text { En las materias del plan de estudios de mi carrera se incluyen temas de } \\
\text { liderazgo }\end{array}$ & .554 & -.342 & .339 & 0.102 & 0.257 & 0.680 \\
\hline En las materias del plan de estudios de mi carrera se fomenta la creatividad & .561 & -.438 & .475 & 0.051 & 0.219 & 0.828 \\
\hline En las materias del plan de estudios de mi carrera se fomenta la innovación & .611 & -.340 & .424 & 0.093 & 0.233 & 0.770 \\
\hline $\begin{array}{l}\text { En las materias del plan de estudios de mi carrera se incluyen temas o } \\
\text { actividades sobre análisis del entorno e identificación de oportunidades }\end{array}$ & .636 & -.319 & .359 & 0.078 & 0.282 & 0.722 \\
\hline $\begin{array}{l}\text { Las materias del plan de estudios de mi carrera existen actividades sobre } \\
\text { asunción de riesgos }\end{array}$ & .530 & -.349 & .249 & 0.134 & 0.303 & 0.606 \\
\hline Tengo materias donde se analiza la tolerancia a los cambios & .529 & -.315 & .277 & 0.123 & 0.269 & 0.610 \\
\hline En mi carrera se fomenta la creación de empresas & .599 & -.192 & .141 & 0.103 & 0.342 & 0.483 \\
\hline Tengo alto nivel de energía y entusiasmo & .582 & .508 & -.018 & 0.679 & 0.075 & 0.064 \\
\hline Tengo confianza en mí mismo & .580 & .577 & .068 & 0.699 & -0.016 & 0.098 \\
\hline Establezco objetivos a largo plazo y me sujeto a ellos & .621 & .451 & .013 & 0.754 & 0.101 & 0.137 \\
\hline Me gusta resolver problemas diferentes & .533 & .532 & .103 & 0.749 & -0.049 & 0.125 \\
\hline Me gusta tomar la iniciativa y me hago responsable del éxito o fracaso & .560 & .549 & -.019 & 0.762 & 0.039 & 0.039 \\
\hline Soy creativo e innovador & .601 & .322 & -.118 & 0.739 & 0.238 & 0.088 \\
\hline Obtengo suficiente información antes de tomar un decisión & .621 & .308 & .031 & 0.686 & 0.160 & 0.212 \\
\hline Disfruto adquiriendo responsabilidades & .522 & .456 & -.033 & 0.763 & 0.070 & 0.054 \\
\hline Me gusta asumir riesgos & .553 & .385 & -.136 & 0.703 & 0.193 & 0.020 \\
\hline Me gusta triunfar por mis propios méritos & .575 & .587 & -.016 & 0.633 & 0.035 & 0.024 \\
\hline Tengo un fuerte deseo de independencia & .482 & .557 & .063 & 0.531 & -0.052 & 0.048 \\
\hline Prefiero crear mi propia empresa que ser empleado & .469 & .510 & .036 & 0.476 & -0.017 & 0.040 \\
\hline Los docentes utilizan estrategias educativas que fomentan la creatividad & .600 & -.552 & -.186 & 0.080 & 0.731 & 0.402 \\
\hline Los docentes utilizan estrategias educativas que fomentan la innovación & .668 & -.493 & -.133 & 0.138 & 0.704 & 0.451 \\
\hline $\begin{array}{l}\text { Los docentes utilizan estrategias educativas que fomentan el trabajo en } \\
\text { equipo }\end{array}$ & .604 & -.025 & -.260 & 0.198 & 0.526 & 0.111 \\
\hline Los docentes promueven el liderazgo & .688 & -.371 & -.289 & 0.158 & 0.761 & 0.287 \\
\hline Los docentes promueven el espíritu empresarial & .677 & -.356 & -.345 & .088 & .788 & .229 \\
\hline Los docentes promueven desarrollo de proyectos emprendedores & .696 & -.353 & -.305 & .124 & .770 & .269 \\
\hline Los docentes emplean simuladores empresariales & .582 & -.449 & -.318 & .066 & .759 & .246 \\
\hline $\begin{array}{l}\text { La mayoría de los docentes tienen experiencia como dueño o socio de una } \\
\text { empresa }\end{array}$ & .427 & -.448 & -.220 & .006 & .607 & .243 \\
\hline \multirow[t]{4}{*}{ Análisis de auto valores } & Total & $\begin{array}{r}\% \text { de } \\
\text { var }\end{array}$ & $\begin{array}{r}\% \\
\text { Acum } \\
\end{array}$ & Total & $\%$ de var & $\%$ Acum \\
\hline & 9.193 & 34.049 & 34.049 & 5.853 & 21.678 & 21.678 \\
\hline & 4.973 & 18.418 & 52.467 & 4.722 & 17.489 & 39.167 \\
\hline & 1.429 & 5.291 & 57.758 & 4.049 & 14.998 & 54.165 \\
\hline
\end{tabular}

Fuente: Elaboración propia con resultados de 315 encuestas.

Carr $=$ Variable dummy para la carrera donde $1=$ Contador Público y $0=$ Licenciado en administración.

Gen $=$ Variable dummy para género, donde $1=$ hombre y $0=$ Mujer.

$\mathrm{PE}=$ Factor de regresión del componente rotado "perfil emprendedor" resultado de ACP.

$\mathrm{RD}=$ Factor de regresión del componente rotado "rol del docente" resultado de ACP.

$\mathrm{FE}=$ Factor de regresión del componente rotado "formación escolar" resultado de ACP.

Debido a que en la variable dependiente "Y" se observa una escala de crecimiento asociada a la experiencia empresarial y/o laboral, se propuso el empleo de los modelos de probabilidad ordenados. De este modo se captura la probabilidad de que una persona incremente su experiencia empresarial o en los negocios, en función de algunas variables personales $\mathrm{y}$ de su percepción sobre la 
empresarialidad propia y del ambiente donde estudia. Las frecuencias de la variable dependiente se presentaron previamente en la tabla 2.

Los modelos de probabilidad ordenados logit y probit se probaron solo con fines de comparación, dado que los resultados en los estimadores de ambos solo son diferentes en su escala (tabla 5). En esta tabla también se presenta la razón de probabilidad (odds ratio) para los estimadores del modelo logit, los cuales son útiles para el análisis de los resultados del modelo.

Como se observa en la tabla 5, a medida que se tiene más edad se incrementa la probabilidad de tener experiencia empresarial. Una persona de más edad es 1.22 veces más probable que tenga experiencias empresariales que otro más joven, manteniendo el resto de las variables constantes. Esto puede ser resultado del ambiente familiar de los estudiantes, dado que en la medida que crecen deben involucrarse en negocios propios o familiares o emplearse, como parte del desarrollo de la persona y las necesidades económicas de la familia.

Si el estudiante es varón implica una mayor probabilidad de tener experiencia empresarial; de hecho un hombre es 1.43 veces más probable que tenga experiencia empresarial que una mujer, manteniendo el resto de las variables constantes. La inversa también tiene sentido: si es mujer la probabilidad de que tenga experiencia emprendedora o en los negocios disminuye. Este resultado puede estar asociado solo con la muestra, dado que en general, la incorporación al mercado laboral es igual para hombres que para mujeres. Sin embargo, si se centra en cuestiones de experiencia en negocios, entonces tiene más lógica, dado que los hombres por lo general dedican un mayor número de horas a lo laboral o empresarial.

El pertenecer a la carrera de contador público $(\mathrm{CP})$ reduce la probabilidad de tener experiencia empresarial; un estudiante de $\mathrm{CP}$ es 0.67 veces menos probable que cuente con experiencia empresarial o laboral que uno de administración. En este sentido, la inversa también aplica: si el estudiante es de administración es más probable que tenga experiencia empresarial.

Si el estudiante tiende a concebirse con un alto perfil emprendedor (es decir que sus respuestas se acercan o tienden a "completamente de acuerdo" en estos aspectos), entonces tendrá más probabilidades de tener experiencia empresarial. Aquellos que se conciban como innovadores, emprendedores, proclives a asumir riesgo, etc. son 1.32 veces más probable que tengan experiencia empresarial que los que tienen una visión negativa de sí mismos. Posiblemente esta alta auto estima empresarial impulse al estudiante a involucrarse en negocios o empleos.

Destaca el hecho de que los estudiantes cuyas opiniones se acercan a "completamente de acuerdo" en cuanto al papel que maestros y planes de estudios juegan para impulsar la cultura emprendedora e innovadora son los que tienen menos probabilidad de tener experiencia empresarial o laboral. Así, quienes tienen una opinión positiva sobre estos aspectos son 0.95 y 0.8 veces menos probables que tengan dicha experiencia empresarial o laboral que aquellos que sean críticos en estos aspectos, manteniendo el resto de las variables constantes. O dicho de otra 
manera los que son más críticos sobre el rol del docente y la formación escolar (con opiniones que se acerquen a "enteramente en desacuerdo") es más probable que tengan mayor experiencia empresarial. Esto significa que el rol del docente y la formación escolar contribuyen negativamente a la experiencia empresarial. Debe decirse que estos 2 resultados solo el de formación escolar es estadísticamente significativo.

En resumen, los resultados de la tabla 5 implican que la mayor experiencia empresarial está asociada a una mayor edad, la carrera de los contables, al género masculino, a concebirse a sí mismo como emprendedor, a ser crítico respecto al ambiente educativo, como el papel del docente y de la formación escolar en el impulso a la cultura emprendedora.

Asimismo, cabe decir que los interceptos (cut 1 y cut 2 de la tabla 5) son significativos, lo que indica que las categorías empleadas (en la variable dependiente, esto es alto, medio y bajo) son adecuadas y no es necesario fusionar a algunas de ellas en una. Finalmente, es importante evaluar las probabilidades de que las variables independientes "caigan" dentro de cada categoría; esto debido a que se trata de variables dicótomas o dummy, y de continuas intrínsecas (factores de regresión). Esto se logra con los resultados de efectos marginales (tabla 6). Como se observa, se presentan los resultados tanto del modelo logit y probit, solo con fines de comparación. El análisis se hará sobre los del modelo logit. 
Tabla 5. Resultados de regresión logística y probit ordenadas

\begin{tabular}{|c|c|c|c|c|c|c|c|}
\hline \multirow[b]{2}{*}{ Variables } & \multicolumn{4}{|c|}{ Modelo logit } & \multicolumn{3}{|c|}{ Modelo probit } \\
\hline & Estimador & $Z^{1 /}$ & & $\begin{array}{c}\text { Razón de } \\
\text { probabilidad }\end{array}$ & Estimador & $z^{1 /}$ & \\
\hline Edad & 0.2036 & 3.4 & *** & $1.2258 * * *$ & 0.12298 & 3.51 & $* * *$ \\
\hline Género $^{2 /}$ & 0.3583 & 1.66 & * & $1.4309 *$ & 0.2103 & 1.62 & * \\
\hline Carrera $^{2 /}$ & -0.3901 & -1.82 & $*$ & $0.6769 *$ & -0.2428 & -1.90 & $*$ \\
\hline Perfil emprendedor & 0.2794 & 2.52 & ** & $1.3223 * *$ & 0.1646 & 2.56 & ** \\
\hline Rol del docente & -0.0487 & -0.45 & & 0.9523 & -0.0241 & -0.38 & \\
\hline Formación escolar & -0.2173 & -1.99 & * & $0.8046 * *$ & -0.1247 & -1.93 & * \\
\hline Intercepto cut 1 & 3.1277 & 2.35 & ** & $3.1277 * *$ & 1.8781 & 2.57 & *** \\
\hline Intercepto cut 2 & 5.0975 & 3.78 & $* * *$ & $5.0975^{* * *}$ & 3.0753 & 4.17 & $* * *$ \\
\hline Test & $\operatorname{LR~Chi}^{2}(6)$ & $\mathrm{Pr}>\mathrm{Chi}^{2}$ & & & $\operatorname{LR~Chi}^{2}(6)$ & $\operatorname{Pr}>$ & $\mathrm{Chi}^{2}$ \\
\hline Razón de verosimilitud & 32.27 & 0.0000 & & & 32.28 & & .0000 \\
\hline
\end{tabular}

Fuente: Elaboración propia con resultados de 315 encuestas.

Notas:

1/ Los asteriscos muestran significancia al: $(*) 10 \%,(* *) 5 \%$ y $(* * *) 1 \%$.

2/ En el caso de la carrera es $1=$ Contador Público y $0=$ Licenciado en administración. En el caso del género $1=$ hombre y $0=$

Mujer. Fuente: Elaboración propia con resultados de 315 encuestas.

Un estudiante de mayor edad incrementa en 4\% la probabilidad de que este en la categoría de alta experiencia empresarial o laboral, o bien disminuye en 3.9\% la probabilidad de que esté en la categoría de nula o baja experiencia.

El ser varón aumenta en $7.2 \%$ la probabilidad de pertenecer a la categoría de alta experiencia empresarial, y reduce en $6.9 \%$ la probabilidad de pertenecer a la categoría baja.

El pertenecer a la carrera de $\mathrm{CP}$ reduce en un $7.8 \%$ la probabilidad de pertenecer a la categoría de alta experiencia empresarial; o bien aumenta en un $6.9 \%$ la probabilidad de pertenecer a la categoría de nula o baja experiencia empresarial. Concebirse así mismo con un alto perfil emprendedor aumenta en $5.6 \%$ la probabilidad de pertenecer a la categoría de alta experiencia empresarial, y reduce en $5.4 \%$ la probabilidad de pertenecer a la categoría de baja experiencia. Una percepción positiva sobre el papel de los docentes en la formación de una cultura de innovación y emprendedora reduce en $0.09 \%$ la probabilidad de pertenecer a la categoría de alta experiencia empresarial y aumenta en $0.09 \%$ la probabilidad de pertenecer a la categoría de baja. Asimismo, una percepción positiva sobre el ambiente escolar de formación académica asociada a la innovación y emprendedurismo reduce en $4.3 \%$ la probabilidad de pertenecer a la categoría de alta; y aumenta en $4.2 \%$ la probabilidad de pertenecer a la categoría de baja experiencia empresarial, tal y como se muestra en la tabla 6. 
Tabla 6. Efectos marginales del modelo logit y probit ordenados

\begin{tabular}{|c|c|c|c|c|c|c|}
\hline \multirow[b]{2}{*}{ Resultado de } & \multirow[b]{2}{*}{ Variables } & \multicolumn{5}{|c|}{ Efectos marginales en experiencia empresarial } \\
\hline & & \multicolumn{2}{|c|}{$\begin{array}{c}1 \text { = nula o baja (1 o } \\
\text { ningún evento) }\end{array}$} & \multirow{2}{*}{$2=$ Media (2 o 3 eventos) } & \multicolumn{2}{|c|}{$3=$ Alta (4 o 5 eventos) } \\
\hline \multirow{6}{*}{ Modelo logit } & Edad & -0.03979 & $* * *$ & & 0.0408 & $* * *$ \\
\hline & Género $^{1 / 2 /}$ & -0.0694 & $* *$ & -0.0027 & 0.0722 & $*$ \\
\hline & Carrera $^{1 /, 21}$ & 0.0761 & $* *$ & 0.0019 & -0.0781 & $* *$ \\
\hline & Perfil emprendedor & -0.0545 & $* *$ & -0.0014 & 0.0560 & $* *$ \\
\hline & Rol del docente & 0.0095 & & 0.0002 & -0.0097 & \\
\hline & Formación escolar & 0.4246 & ** & 0.0011 & -0.0435 & $* *$ \\
\hline \multirow{6}{*}{ Modelo probit } & Edad & -0.0405 & $* * *$ & -0.0008 & 0.0414 & $* * *$ \\
\hline & Género & -0.0689 & & -0.0021 & 0.0711 & \\
\hline & Carrera $^{1 /}$ & 0.0800 & $* *$ & 0.0016 & -0.0816 & $* *$ \\
\hline & Perfil emprendedor & -0.0543 & $* *$ & -0.0011 & 0.0554 & $* *$ \\
\hline & Rol del docente & 0.0079 & & 0.0001 & -0.0081 & \\
\hline & Formación escolar & 0.0411 & $* *$ & 0.0008 & -0.0420 & $* *$ \\
\hline
\end{tabular}

Fuente: Elaboración propia con resultados de 315 encuestas.

Notas :

1/ El efecto marginal (dy/dx) de la variable dummy evalúa un cambio discreto, al pasar de 0 a 1 .

2/ En el caso de la carrera es $1=$ Contador Público y $0=$ Licenciado en administración. En el caso del género $1=$ hombre y $0=$ Mujer.

(*) Significativo al 90\% de confianza. (**) Significativo al 95\% de confianza. (***) Significativo al $99 \%$ de confianza.

Finalmente se presentan los resultados de la prueba de Brant para evaluar el supuesto proporcional de probabilidades de la regresión logística ordenada (también llamado modelo de líneas paralelas). Estos resultados se presentan en la tabla 6, que consiste en una serie coeficientes de regresiones binarias logísticas, del siguiente modo: categoría 1 vs categorías 2 y 3 , y categorías 1 y 2 versus 3 . Si el supuesto de líneas paralelas no es violado significa que todos los coeficientes (excepto los de los interceptos) de estas regresiones serán los mismos. Como se observa, este problema se presenta principalmente para la variable "Rol del docente" y en menor medida para "Formación escolar"; para el resto de los coeficientes la variación es mínima. En este sentido, y debido a las implicaciones y construcción del modelo se decidió continuar y basar los análisis en el modelo ordenado.

Tabla 7. Resultados de la Prueba de Brant de STATA

\begin{tabular}{|c|c|c|c|c|c|}
\hline \multirow[b]{2}{*}{ Variable } & \multicolumn{2}{|c|}{ Estimadores de regresiones binarias j-1 } & \multicolumn{3}{|c|}{ Prueba de Brant para el supuesto de regresión paralela } \\
\hline & $y>1$ & $y>2$ & Chi2 & prob $>$ Chi2 & gl \\
\hline Edad & 0.2168 & 0.2018 & 0.03 & 0.857 & 1 \\
\hline Género & 0.3682 & 0.3558 & 0.00 & 0.967 & 1 \\
\hline Posee carro & -0.4953 & -0.3179 & 0.37 & 0.546 & 1 \\
\hline Perfil empresarial & 0.2363 & 0.3436 & 0.48 & 0.488 & 1 \\
\hline Rol del docente & -0.1495 & 0.0665 & 2.21 & 0.137 & 1 \\
\hline Formación escolar & -0.1141 & -0.2853 & 1.52 & 0.218 & 1 \\
\hline Constante & -3.3466 & -5.1045 & & & \\
\hline Todas & & & 5.16 & 0.524 & 6 \\
\hline
\end{tabular}

Notas: La prueba proporciona evidencia de que el supuesto de regresión paralela ha sido violado. 


\section{CONCLUSIONES}

De la presente investigación se desprenden una serie de conclusiones relevantes que nos permiten entender las intenciones de emprendimiento entre los, así como la relación existente entre el rol docente, la formación escolar y el entorno y experiencia de los estudiantes con el desarrollo competencias emprendedoras (perfil emprendedor) de los mismos.

Estas conclusiones se derivan de los resultados obtenidos a través de la metodología utilizada para poder alcanzar el objetivo general del estudio, resolver las preguntas de estudio y comprobar las hipótesis planteadas.

A continuación se presentan conclusiones concretas derivadas de los resultados obtenidos en el presente trabajo.

Con relación a las intenciones emprendedoras de los estudiantes, se resalta lo siguiente:

- Quienes se conciben a sí mismos con un alto perfil emprendedor, son quienes tendrán mayores probabilidades de emprender un negocio.

- De acuerdo a los resultados se observó que existe una mayor probabilidad de intención emprendedora en los estudiantes de la carrera Licenciado en Administración.

- La probabilidad de emprendimiento es mayor en los hombres que en las mujeres.

- Los estudiantes de mayor edad son quienes más probabilidad tienen de ser empresarios.

Con respecto al rol que asume el docente, se destacan las siguientes conclusiones:

- Los estudiantes que opinan positivamente que los docentes promueven el espíritu empresarial, son quienes tienen menor probabilidad de ser emprendedores.

- Comprobando la afirmación anterior, son las mujeres, los estudiantes de la carrera de C.P y los estudiantes de menor edad quienes tienen la percepción positiva de que los docentes promueven el espíritu empresarial.

Con relación a la percepción de la formación escolar (plan de estudios), se destaca lo siguiente:

- Al igual que en el apartado anterior, los estudiantes que opinan positivamente que en su carrera promueven el espíritu empresarial, son quienes tienen menor probabilidad de ser emprendedores. 
- Así pues, comprobando la afirmación anterior, son las mujeres, los estudiantes de la carrera Contable y los estudiantes de menor edad quienes tienen la percepción positiva de que en su carrera se promueve el espíritu empresarial.

Con base en los resultados obtenidos en cuanto a la experiencia de los estudiantes se resalta lo siguiente:

- Los estudiantes de la carrera de Licenciado en Administración tienen mayor experiencia laboral desempeñando trabajos en áreas funcionales de alguna empresa.

- Los hombres tienen mayor experiencia laboral desempeñando trabajos en áreas funcionales de alguna empresa.

- Los estudiantes de mayor edad tienen mayor experiencia laboral desempeñando trabajos con áreas funcionales de alguna empresa.

Así mismo, de acuerdo a los resultados obtenidos del modelo aplicado, se concluye que existe una relación estadísticamente significativa entre las variables independientes con la variable dependiente. Sin embargo, en dos de ellas la significancia resulta negativa. Lo cual nos permite verificar que una de las hipótesis planteadas se comprueba y las otras dos se convierten en hipótesis nulas. Y por lo tanto se da también respuesta a las preguntas de investigación.

Tomando en cuenta lo anterior, concluimos que una hipótesis se confirma y dos se convierten en hipótesis nulas, por lo tanto podemos decir qué:

- Los programas educativos del área Contable y Licenciado en Administración a partir del contenido de las materias no propician positivamente el desarrollo de competencias de los estudiantes en materia de innovación, creación, asunción de riesgos y habilidad para planificar y gestionar proyectos por cuenta propia.

- El rol que asume el docente influye negativamente en el fortalecimiento del espíritu empresarial en los estudiantes.

- La percepción positiva del estudiante sobre sí mismo en cuanto a su perfil emprendedor y sus aspiraciones empresariales sí influye positivamente en el desarrollo y fortalecimiento de sus competencias emprendedoras

A manera de conclusión, podemos decir que con base en los resultados obtenidos, se alcanzó el objetivo general planteado, logrando identificar las causas que influyen en el desarrollo de competencias emprendedoras de los estudiantes. Así como los objetivos particulares, los cuales están directamente vinculados con el objetivo general. 
Por lo tanto, causas de influencia positiva en el desarrollo competencias emprendedoras, es la percepción positiva del estudiante sobre sí mismo en cuanto a su perfil emprendedor y sus aspiraciones empresariales.

Es importante mencionar que las otras dos variables que en cierta medida influyen negativamente en el desarrollo de competencias de los estudiantes en materia de innovación, creación, asunción de riesgos y habilidad para planificar y gestionar proyectos por cuenta propia son: el rol docente y la formación escolar.

Tomando en cuenta lo anterior, desde nuestro punto de vista, el emprendimiento debe plantearse seriamente como una opción profesional real entre los estudiantes, de tal manera que al momento del egreso tengan otra opción más para su desarrollo profesional.

Las universidades deben ser de vanguardia. El pretender obtener un rol mayor en el desarrollo de una cultura emprendedora, implica más que sólo el apoyo de emprendimientos a través de programas que cumplan tales objetivos.

Por lo tanto, es de vital trascendencia, buscar alternativas a partir de la enseñanza desde las carreras, que fomenten una real formación entre los estudiantes como verdaderos emprendedores que funjan como generadores de cambio en nuestra sociedad y así poder revertir esa influencia negativa.

\section{BIBLIOGRAFÍA}

ÁLVAREZ C. Y MORENO C. Formación basada en competencias emprendedoras para la modernización del Estado; España: 2002. VII Congreso Internacional del CLAD sobre la Reforma del Estado y de la Administración Pública, Lisboa, Portugal, 8-11.

AMORÓS, J. E. El Proyecto Global Entrepreneurship Monitor (GEM): Una Aproximación Desde el Contexto Latinoamericano Academia. Revista Latinoamericana de Administración, Universidad del Desarrollo, Santiago de Chile, (46), 2011, p.1-15.

BARON, A.; SHANE SCOTT, A. Entrepreneurship, a process perspective. Thomson, 2008. 479 p. ISBN 13:978-0-324-36558-6.

BELLOCCHIO, M. Educación basada en competencias y constructivismo: un enfoque y un modelo para la formación pedagógica del Siglo XXI. México: 2010. ANUIES.

CABELLOS DÍAZ, C. Emprendedurismo dentro del ámbito universitario (2006). Recuperado el 29 de septiembre de 2011 de http://www.uv.es/motiva/MarDelPlata06/Ponencias/ponenciaCandidaCabello.pdf

CARTER, R.; H. VAN AUKEN "Small Firm Bankruptcy," Journal of Small Business Management, Vol. 44, No. 4. 2005. p. 493-512. 
CASTILLO, A. Estado del Arte en la Enseñanza del Emprendimiento dentro del marco del proyecto. "Emprendedores como Creadores de Riqueza y Desarrollo Regional". 1999. p. 22. INTEC. Chile. ARI2487-INV/ENSE.

CASTILLO, C.; ORLANDO, J. Círculo virtuoso de la educación empresarial: una propuesta de modelo para el desarrollo de un tejido empresarial de calidad. Revista-Escuela de Administración de Negocios, Universidad EAN Colombia, 63. 2008. p. 23-39.

CAMPOS, G. Y SÁNCHEZ, G. La vinculación universitaria: Ese oscuro objeto del deseo. Revista Electrónica de Investigación Educativa, vol. 7 (2), 2005. Recuperado el 19 de agosto de 2011 de http://redie.uabc. mx/vol7no2/contenido-campos.html .

COMISIÓN DE LAS COMUNIDADES EUROPEAS. Libro Verde, el Espíritu Empresarial en Europa. 2003. Bruselas, Bélgica.

ESCOBAR VALENCIA, M. Las competencias laborales: ¿la estrategia laboral para la competitividad de las organizaciones?. Estudios Gerenciales. 96. 2005. p. 31-55.

GUTIÉRREZ SIVIRA, F. Desarrollo local - endógeno y el papel de las universidades en la formación de cultura emprendedora e innovadora en territorios socio-deprimidos; Laurus, vol. 12, (22), 2006. p. 139-152

JACKMAN, S. Models for Ordered Outcomes. Course papers. 2000. Available at: http://www.stanford.edu/class/polisci203/ordered.pdf.

KRAUSS, C. Las actitudes emprendedoras en los estudiantes de la Universidad Católica Del Uruguay. Dimens. empres. - Vol. 9 No. 1. 2011. p. 28-40.

LÉVY-LEBOYER, C. Gestión de las competencias: cómo analizarlas, cómo evaluarlas, cómo desarrollarlas Barcelona: Gestión 2000. (2003). 161 p. ISBN 9788480881784 .

LÓPEZ, W.; MONTILLA, M. Y BRICEÑO, M. Rasgos determinantes de las aptitudes emprendedoras que forman el perfil de los estudiantes de Contaduría Pública. Actualidad contable FACES. Vol. 10 (14). (2007). p. 80-94.

MARTÍNEZ, F. Y CARMONA, G. Aproximación al concepto de competencias emprendedoras: valor social e implicaciones educativas. Revista Iberoamericana sobre Calidad, Eficacia y Cambio en Educación, vol. 7, (3). 2007. p. 82-98.

MARTÍNEZ RODRÍGUEZ, F.M. Análisis de competencias emprendedoras del alumnado de las escuelas taller y casas de oficios en Andalucía. Primera fase del diseño de programas educativos para el desarrollo de la cultura emprendedora entre los jóvenes. Tesis Doctoral publicada por la Universidad de Granada España. 601 p. ISBN-978-84-691-8339-7.

MARTÍN, N. HERNANGÓMEZ, J. Y RODRÍGUEZ, A. Análisis de la formación y la experiencia laboral como determinantes del espíritu emprendedor de los estudiantes universitarios. Revista Asturiana de Economía - RAE, Universidad de Valladolid, Vol. 34. 2005. p. 131- 145. 
MORALES GUALDRÓN, S. El emprendedor académico: su perfil y motivaciones para convertirse en empresario. Tec Empresarial, vol. 4 (2). 2010. p. 9-20

ORREGO CLARA I. (2008). La dimensión humana del emprendimiento. Revista Ciencias Estratégicas, Vol. 16, (20), pp. 225-235.

PASWAN, A., M. D. SANTARRIAGA PINEDA Y F. C. SOTO RAMÍREZ Small versus large retail stores in an emerging market - Mexico. Journal of Business Research. 63. 2010. p $667-672$.

PEREDA, S. Y BERROCAL, F. Gestión de recursos humanos por competencias. Madrid: Editorial Centro de Estudios Ramón Areces. (2001). ISBN 9788480043960.

PROYECTO DESECO. Definición y selección de competencias clave: resumen ejecutivo. (2002). Recuperado el 18 de marzo de 2013 http://www.deseco.admin.ch/bfs/deseco/en/index/03/02.parsys.78532.download List.94248.DownloadFile.tmp/2005.dscexecutivesummary.sp.pdf 